\title{
The research of personal and professional development features of college graduates in the university: content and methods
}

\author{
Yanina Morozova ${ }^{1, *}$ and Inessa Kuzheleva ${ }^{1}$ \\ ${ }^{1}$ Don State Technical University, Sq. Gagarina 1, Rostov-on-Don, Russia
}

\begin{abstract}
The features of the personal and professional development of the future specialists are studied in the aspect of their specialization. These are revealed through the use of projective research methods - the essays "My professional plans" and "My usual day in ... years", incomplete sentence method, and a questionnaire to assess the level of socio-psychological adaptation. To study the college graduates' adaptation peculiarities to educational process in the university, the questionnaire was used, designed to determine the level of educational and professional adaptation in psychophysiological, professional and socio-psychological aspects. The article describes the use of the "Incomplete sentences" method, its modification depending on the indicators of the respondents group. The results of testing students are presented in detail. Other research methods are also described.
\end{abstract}

\section{Introduction}

During the period of study in college, which also coincides with high school age, a college graduate decides how to use his abilities and how to realize himself in work and in life itself. In general, this allows us to say about a special sensitivity to social, professional and personal self-determination.

Since in this period a person first comes into direct contact with society, then his main task is to solve social problems: the choice of a profession, the acquisition of a certain social status. Therefore, special research attention should be paid to the factors concerning the social aspect of the subject's entry into adult-hood and changes in the social situation of the graduate's development.

The ability to work in a team, communication activity, the ability to resolve conflicts, endurance, etc., necessary for personal and professional development are components of social competence.

The socialization of the subject is determined by quantitative and qualitative characteristics. Therefore, quantitative characteristics refer to the whole variety of learned normative units of socialization, qualitative ones - the degree of stability, depth and success in the application of acquired social norms, values, rules. The formation of social competencies of college graduates involves the gradual replacement of purely cognitive

\footnotetext{
* Corresponding author: yanina.frost@mail.ru
} 
activities with socially significant ones with an adequate change in needs, goals, means, actions and behavior. The goal of the educational institution is the complex development of the personality, corresponding to the currently specific socialization norm, one of which is the adaptation of college graduates to the process of studying at the university.

The modern vocational education system is implemented through the process of continuous education in the sequence "lyceum - college - university". In Rostov-on-Don, the lifelong learning model is implemented at the Institute of Management, Business and Law (at SFU) and at the Don State Technical University (DSTU).

The study was conducted in order to identify the psychological specifics of the educational system of the college, study the characteristics and dynamics of personal and professional development of students in the system of continuing education "college university", as well as to determine the problematic aspects of the development of college graduates. The features of the professional development of college graduates at the university were identified using projective research methods - the essays "My professional plans" and "My usual day in ... years", methods of incomplete sentences and a questionnaire to assess the level of socio-psychological adaptation.

\section{Materials and methods}

The technique of "Incomplete sentences" ("sentence completion") (Payne, Tendler) was created in order to identify the characteristics of the ideas, relationships of the individual. It's different variants were used by J. Potter, D. Sachs, B. Forer and others [8]. The research methodology "Incomplete sentences" by Sachs and Levy belongs to the group of projective tests and is used in psychological practice to study the features of human relations system to different groups of people (to the family, to the chief, etc.), the past and the future, towards life goals, etc.

This technique has great diagnostic capabilities and is used in psychological research in various modifications corresponding to the subject and goals of scientific analysis. In particular, in a number of works, the "Incomplete sentences" technique was used in different versions:

- to study the peculiarities of the attitude of psychology students to the psychological profession [5],

- to study the opinion of entrepreneurs about significant events of the past, present and future [6],

- to study the value-semantic sphere of high school students, to identify that they have problems of an existential nature and to study their demand for psychological support [2],

- to clarify the professional plans and expectations of law students [3], etc.

The "Incomplete sentences" method was modified in accordance with the empirical study objectives of the specifics of the personal and professional development of university students who graduated from college in accordance with chosen specialty.

This method was offered in three variants, depending on the indicators of the respondents group: college students; university students who studied in college; university students who have not undergone pre-college education. The "Incomplete sentences" technique was used to identify:

1) the determinant of the students' choice of a given college and institute, as well as the level of awareness of this choice;

2) matching the reasons for entering college with a professional choice;

3) ideas about the profession, about a professional career among students who graduated from college and among students of the institute who did not study at college;

4) professional plans of students; 
5) students' ideas about the subjective and objective difficulties of the study at the institute;

6) the peculiarities of the perception of each other by students who studied in college and those who did not undergo preliminary training in college;

7) students' ideas about their abilities, opportunities and desires both in training and in the process of further professionalization.

\section{The results}

During the analysis of each group of sentences, the categories allocated for content analysis were used. Conducting content analysis, a thematic calculation of the frequency mentions of content analysis units identified by us for each category in a unit of text was carried out. The unit of the text was an essay and a filled-in with the sentences form of one student. Quantitative indicators of references frequency of the categories of quantification were further subjected to mathematical processing. Quantitative indicators determined the completeness and degree of expression of each category.

In the studies of Russian psychologists, such a variant of the "Storytelling" method, as an essay, is often used. In particular, the essays "My professional plans" and "My usual day in ... years" are used to study the specifics of life, including professional plans. Information about such techniques is contained both in works devoted to the diagnosis of professional plans and ideas, and in works that offer variants for psychological exercises for psychological correction of this sphere of personality. [1, p.47; 5, p.90].

Students were offered to write an essay on a given topic (they were asked to describe their professional plans and present their working day in a few years and describe it). At the same time, the task was not concretized by questions or explanations. Taking into account the fact that the diagnostic capabilities of projective techniques are quite wide and varied, the processing was carried out only according to clearly defined criteria using the method of statistical (quantitative) semantics (content analysis).

The projective method of essays presupposes the absence of a given direction of the respondents' thoughts (as opposed to the method of "Incomplete sentences") and makes it possible to identify the peculiarities of professional plans and career projects, the specifics of the attitude to the future profession, presented directly in the minds of students. The use of two projective methods simultaneously makes it possible to clarify the obtained data, increases the reliability of the research results.

In the qualitative analysis of students' essays on the topic "My usual day in ... years", the following categories of content analysis were used: ideas about the level of possible career advancement (the level was defined as high, medium or low); ideas about the desired quality of life; description of working conditions and labor actions; subjective satisfaction with imaginary achievements; peculiarities of the daily routine (three modes were identified - full workload, free schedule and standard); mention of privacy.

The listed categories have been combined into three blocks, the content of which characterizes the following:

- ideas of students as realistic or unrealistic,

- ideas of students as detailed or non-detailed,

- ideas about a successful career in general or the idea of a specific chosen professional activity;

- subjective satisfaction with the content of the predicted future.

The projective essay "My professional plans" involved the drafting of texts by students on a clearly defined topic, taking into account specific questions, the proposed instructions ("What are my professional plans?", "What do I want and what can I achieve in the 
profession?", "Will I work in my specialty or will I have another professional future?", "What do I need to do to make my professional career take place?").

The works of the students "My professional plans" were also processed using the contentanalysis method. Let us list the main characteristics of professional plans, indicating the level of their development, formation and stability of professional orientation, the success of the professionalization process:

- the presence of the main goal, a chain of immediate and more distant goals;

- indication of the way and means of achieving immediate goals;

- external conditions for achieving goals;

- internal conditions for achieving goals;

- fallback options for goals and ways to achieve them;

- realness of plans (awareness of obstacles, concordance with their abilities and capabilities, real time periods, the level of predicted positions in relation to the timing of their achievement (subject to independent achievement));

- definiteness (an indication on employment options, a description of labor actions, a description of the stages of a professional career);

- a positive attitude towards the profession and confidence in the possibilities of career growth.

Subsequently, the quantitative processing of the test results was carried out according to the following scheme:

- development of criteria and principles of scoring for the level of formation of students' professional plans using the method of expert assessments through the experience of practical researches;

- determination of three levels of professional plans formation: high, medium, low or unformed;

- assessment of the level of professional plans formation in student works;

- assessment of the general level of formation of professional plans and average group trends for each indicator.

Analyzing the texts of the essays "My professional plans" and "My usual day in ... years" the method of intent analysis was used. This method was developed in the Laboratory of Speech and Psycholinguistics of the Institute of Psychology of the Russian Academy of Sciences in order to study the deep psychological content of speech, which lies in the socalled intentional layer, i.e. in intentions, indirectly manifested in words [4, p.90].

Processing the data, an assessment scale was used in the form of an axis, in the center of which statements with a neutral assessment were noted, on the right side - with positive and emphatically positive, and on the left - with negative or emphatically negative answers. At the next stage, in the course of a continuous, non-selective study of the text, a set of meaningful intentions was revealed, which are either openly declared by the author, or are expressed indirectly.

\section{Discussion}

In the process of solving the described tasks, the listed categories of quantification were determined as criteria for the level of professional plans formation. Among the mandatory indicators, the following indicators are highlighted: the presence of main and intermediate goals, realism, certainty, understanding the ways and means of achievement, awareness of the necessary conditions for achieving, goals and possible obstacles, the correspondence of professional plans to the main direction of study at the university.

The level of formation of professional plans was assessed as high in the presence of all the listed indicators and detailed characteristics of some of them. The level of formation of professional plans was determined as the medium in the presence of half of the listed 
indicators or in the presence of all the named criteria, but with a brief presentation (general statements, formal, vague, without time restrictions, in an indicative presentation, in which, for example, the possibility of obstacles to achieving professional success are stated, but their variants are not described). A low level of professional plans formation was recorded in the absence of a larger number of the listed criteria, when professional plans did not correspond to the profile of university education, when the text was defined as an emotional statement (confidence, hope) or a description of a dream without any specification. At the same time, the genre of the essay resembles the text obtained as a result of the application of the method "My usual working day in ... years".

To study the peculiarities of adaptation of college graduates to the process of education at a university, a questionnaire was used to assess the level of social and psychological adaptation [7]. The specified questionnaire is intended to determine the level of educational and professional adaptation, which is the unity of an individual's adaptation to the physical conditions of the educational and professional environment (psychophysiological aspect), adaptation of the activity subject or subject of training to professional and educational tasks, labor tools and teaching aids, operations performed, etc. (actually the professional aspect) and adaptation of the individual to the social components of the educational and professional environment (social and psychological aspect).

As the criteria for socio-psychological adaptation in this questionnaire, the attitude towards a manufacturing enterprise, organization (large group), attitude towards a small group, attitude towards a leader, satisfaction with relations with employees are defined. General indicators of adaptability are satisfaction with the content and working conditions. Questions related to the study of relations with employees were reformulated in order to study relations in the student group and in the institute as a whole, questions about leaders were redirected to teachers and curators of groups, and the work environment and activities in general were changed to educational and professional activities.

Processing the students' test results, the following data were obtained:

- the general level of adaptation to the learning process at the university, which was defined as high, expressed, low, or as maladjustment;

- the level of adaptation for each scale of the questionnaire (which correspond to the specified criteria).

To answer the question about the significance of the obtained differences in the level of adaptation of college graduates in the university and students who did not study in college, mathematical methods of data processing were used.

The methods of expert assessment and individual conversations made it possible to turn to teachers who carry out educational and professional training of students. The method of expert assessments was used to solve the following practical problems:

- highlighting the categories of quantification and determining the degree of their expression for the methods of "Incomplete sentences" and the essay "My usual working day in ... years";

- assessment of college students' training specifics.

In the first case, teachers of psychological disciplines acted as experts, in the second curators of groups and teachers who train students both in college and at the university.

\section{Conclusion}

The study of the personal and professional development peculiarities of university students was based on the comparative characteristics of the data of two conditional groups of students: those who had previously studied in college and those who did not have such experience. Such a comparative analysis contributed to the identification of both 
psychological advantages and problem areas of students' professionalization included in the system of lifelong education.

The results of the study made it possible to determine the average indicators of the level of adaptation of college graduates in the educational area of the university, to obtain comparative data on their level of adaptation and the level of adaptation of university students who had not previously studied in college, as well as to make a qualitative analysis of the most favorable or difficult lines of adaptation processes of university students.

\section{References}

1. A.F. Berezin, The development of the subjectivity of psychology students in the process of independent educational activity. diss. cand psychol. sciences (Stavropol, 2002)

2. N.N. Zagryadskaya, Psychological support for high school students in solving existential problems. diss. cand. psychol. sciences (Rostov-on-don, 1999)

3. F.Kh. Koichueva, Psychological support for the personal and professional development of law students. diss. cand. psychol. sciences (Stavropol, 2005)

4. O.A. Lapshova, M.V. Shelomentseva, Xth International scientific and practical conference "Socio-psychological problems of mentality/mentality" (Smolensk, 2012)

5. A.R. Musalaeva, Features of the formation of the professional orientation of psychologists during the period of higher education. diss. cand. psychol. sciences (Stavropol, 2004)

6. V.N. Petrievsky, Psychological features of personal self-determination of a successful entrepreneur. diss. cand. psychol. Sciences (Stavropol,, 2002)

7. A.A. Krylova, S.A. Manicheva, Workshop on general, experimental and applied psychology (SPb, 2003)

8. D.Ya. Raigorodsky, Practical psychodiagnostics. Techniques and tests (Bakhrakh-m., Samara, 2011) 